\title{
Increased responsiveness to cholinergic stimulation of small compared to large diameter cartilaginous bronchi
}

\author{
H.W. Mitchell, M.P. Sparrow
}

Increased responsiveness to cholinergic stimulation of small compared to large diameter cartilaginous bronchi. H.W. Mitchell, M.P. Sparrow. OERS Journals Ltd 1994.

ABSTRACT: Model studies incorporating known morphological properties of the airways predict different narrowing characteristics between large and small bronchi. However, the flow-response characteristics of airways from different regions in the bronchial tree are still unknown.

We compared the responsiveness of large and small bore bronchi of the pig to luminal or adventitial stimulation by acetylcholine (ACh) during perfusion of the airways at optimal driving pressure. Subsequently, each segment was measured morphometrically. Resting flow through the lumen was directly related to the fourth power of the segment internal diameter (ID). The sensitivity of small bronchi $(2.00 \mathrm{~mm}$ ID) to ACh applied adventitially was about 870 times greater than large $(5.85 \mathrm{~mm}$ ID) with a longer latency time of contraction in large bronchi.

When perfused luminally the sensitivity difference was $\mathbf{4 2}$ fold, and after removing the epithelium the sensitivity difference was reduced to approximately five fold. Maximum concentrations of ACh produced airway closure in small segments $(100 \%$ reduction in flow) but in large segments a plateau developed at $60-90 \%$ flow reduction. Similar findings were obtained with carbachol. Morphometry of the airway wall showed increasing cartilage, mucosal and smooth muscle thickness with increasing diameter, but a decreasing relative wall area.

The marked differences in sensitivity to narrowing between large and small bronchi are, in part, related to differences in morphological properties of the mucosa (the epithelium) and adventitia, and to airway location. Airway size plays an important role in the maximum response of airway narrowing, with small airways showing closure and large airways a plateau.

Eur Respir J., 1994, 7, 298-305.
Dept of Physiology, University of Western Australia, Nedlands, Australia.

Correspondence: H.W. Mitchell Dept of Physiology

University of Western Australia

Nedlands 6009

Australia

Keywords: Airway smooth muscle bronchial morphology

bronchial responsiveness

epithelial-derived inhibitory factor

Received April 301993

Accepted for publication September 91993

This work was supported by the National Health and Medical Research Council of Australia and the Ada Bartholomew Medical Research Trust.
The responsiveness of the human or animal airway is commonly defined from the position, or less often the slope or maximum effect, of a dose-response curve to a provocative agent, such as a cholinomimetic. The provocative dose (e.g. $\left.\mathrm{PD}_{20}\right)$ and maximum response vary in different individuals, and this is often associated with the presence or severity of asthma [1], and inflammatory or immunological stimulation in animals [2, 3]. Bronchial responsiveness in vivo, i.e. the shape of the dose-response curve to provocative stimulation, is determined by a relationship between airway activation and airway narrowing at different locations in the bronchial tree. A major pressure drop occurs in segmental and subsegmental airways in man and in dogs [4-6], and in vivo techniques have shown narrowing of the lumen of large $(\sim 10 \mathrm{~mm})$ and small (1-2 $\mathrm{mm})$ bronchi in the lung of dogs in response to injection of intravenous bronchoconstrictors and to stimulation of the vagal nerves [7, 8], suggesting that these airways contribute to bronchial responsiveness.

Narrowing of airways is caused by the contraction of the smooth muscle, but it is also dependent on other characteristics of the airway wall, which may differ in air- ways from central to peripheral sites. Some of the properties of the airway wall which are important to the narrowing response in isolated airways have recently been examined, using isolated perfused segments of small bronchi ( $\sim 2 \mathrm{~mm}$ internal diameter (ID)). In bronchi of this size, the permeability of the surface exposed, for example the lining epithelium [9], is particularly important to the response; removing the epithelium causes an approximately, 30 fold increase in sensitivity to luminally applied acetylcholine. In isovolumic bronchial segments, the transmural pressure alters the responsiveness, with a reduction in active pressure to field stimulation as luminal pressure increases above about $10 \mathrm{cmH}_{2} \mathrm{O}$ [10]. Furthermore, simulations incorporating known morphological properties of airways, suggest that narrowing will be greatest in airways that have a high relative wall area $[11,12]$, and the slope of the dose-response curve for muscle shortening versus resistance will be increased [13-15]. However, the flow-response characteristics to varying concentrations of provocative stimulation in individual isolated airways from different regions of the bronchial tree are, as yet, unknown. 
Accordingly, the present paper reports studies on the responsiveness of pig perfused bronchi in vitro, under conditions where airway size, route of drug delivery and driving pressure were predetermined. We compared responses to a drug placed adventitially and mucosally, and mucosally either with or without an intact epithelium. The thickness of the adventitia (cartilage) and mucosa were determined morphometrically in different sized airways, because the diffusion distance to the smooth muscle layer may affect the activation of the smooth muscle to drugs and, therefore, airway narrowing. A preliminary account of some of the findings were presented at a satellite meeting of the XIth International Congress of Pharmacology [16].

\section{Materials and methods}

\section{Preparation of bronchial segments}

Lungs were removed from $35 \mathrm{~kg}$ pigs immediately after slaughter. Bronchial segments, dissected on ice, were taken from the "stem" bronchus of a lower lobe [17]. Bronchi of varying ID were studied, by selecting from either the proximal or distal ends of the "stem" bronchus. Segments $(2.5 \mathrm{~cm}$ long) were initially placed into groups, according to their estimated ID. The ID was initially estimated by comparing the lumen with machined metal rods of known diameter inserted just into the distal (i.e. narrow) end of the segment. We aimed at studying groups of segments with the following approximate IDs: $1,1.5,2,3,4$ and $5 \mathrm{~mm}$. The $1 \mathrm{~mm}$ segments were the smallest that could be prepared without damage to the airway, whilst the $5 \mathrm{~mm}$ segments were the largest which could be obtained close to the bronchial bifurcation. At the conclusion of the experiments, the ID of each segment was accurately measured morphometrically (see below). The IDs from the morphometric analyses were larger than those initially estimated, and the data are presented in the Results section below.

A bronchial segment of the desired ID was cannulated at each end, with cannulae of at least the same ID as the distal end of the segment. All side branches were tied-off close to the wall of the "stem" bronchus. Cannulated segments were then fixed to the perfusion apparatus described previously for detecting flow rate using a custom-built flow head [9]. Bronchial segments were perfused through the lumen, and bathed on the outside, with a Krebs solution in a chamber of approximately $35 \mathrm{ml}$ capacity. Segments were submersed to a depth of about $0.5 \mathrm{~cm}$ below the surface of the Krebs solution. The composition of the Krebs solution was (mM): $\mathrm{NaC} 1$ (121), $\mathrm{KCl}$ (5.4), $\mathrm{MgSO}_{4}$ (1.2), $\mathrm{NaH}_{2} \mathrm{PO}_{4}$ (1.2), $\mathrm{NaHCO}_{3}$ (25), glucose (11.5) and $\mathrm{CaCl}_{2}(2.5)$. The solution was buffered to $\mathrm{pH} 7.4$ with 3-[N-morpholino]propane sulphonic acid $(5 \mathrm{mM})$.

The pressure drop caused by the flow of Krebs solution along the flowhead was measured with a previously calibrated Motorola (type MPX10DP, Motorola Semiconductors, Phoenix, USA) differential pressure transducer. The perfusion pressure of $5 \mathrm{cmH}_{2} \mathrm{O}$ was set by the height of the reservoir containing the Krebs solution. Flow and pressure were linearly related both in resting and constricted bronchial segments [17], indicating that flow was essentially laminar.

Particular care was taken to match the resistances of the bronchial segment and apparatus (mainly the flowhead), at least as closely as practicable, so that the sensitivity of the recording device was optimum, and to prevent bias in the recorded dose-flow relationship obtained in different sized segments. Threshold responses (change in flow rate) are dampened if apparatus resistance exceeds segment resistance excessively. We therefore measured the resistance of the resting segment and the apparatus in each experiment, utilizing different sized airway segments. Segment resistance was estimated by subtracting total resistance from apparatus resistance. Total resistance (apparatus and bronchial segment) was calculated by dividing the pressure head by the flow rate. Apparatus resistance was determined from the flow rate after replacing the bronchial segment with a short length of large-bore plastic tubing. Bronchial and apparatus resistances were closely matched, e.g. in one of the airway sizes most studied (2.00 mm ID, see Results) mean segment resistance $(\mathrm{n}=6-9)$ was $0.134 \pm 0.025 \mathrm{cmH}_{2} \mathrm{O} \cdot \mathrm{ml}^{-1} \cdot \mathrm{min}$ and apparatus resistance $0.1 \mathrm{cmH}_{2} \mathrm{O} \cdot \mathrm{ml} \cdot \mathrm{min}^{-1}$. In large segments $(5.85 \mathrm{~mm} \mathrm{ID)}$ it was $0.004 \pm 0.0001$ and 0.0061 $\mathrm{cmH}_{2} \mathrm{O} \cdot \mathrm{ml}^{-1} \cdot \mathrm{min}$. Accordingly the total pressure drop of $5 \mathrm{cmH}_{2} \mathrm{O}$ was divided about equally between the bronchial segment and the flowhead, and the downstream ends of both the large and small segments would, therefore, be subjected to a transmural pressure approaching $2.5 \mathrm{cmH}_{2} \mathrm{O}$ during flow. This pressure would be expected to rise towards a maximum of $5 \mathrm{cmH}_{2} \mathrm{O}$ in the event that the downstream airway closed.

The sensitivity and maximum response (flow rate) to acetylcholine were studied in segments with distal IDs described above. After leaving the perfused segment to equilibrate for $>1 \mathrm{~h}$, it was stimulated either with electric field stimulation (EFS, $60 \mathrm{~V}, 2 \mathrm{~ms}, 20 \mathrm{~Hz}$ for a $30-45 \mathrm{~s}$ train) and/or with a submaximal concentration of acetylcholine.

After wash-out and recovery, a cumulative concentration-response curve to acetylcholine was then obtained. In most experiments, one curve was obtained to the drug perfused through the lumen and one when the drug was placed on the outside (i.e. adventitial surface). Whilst the stimulus was being applied, the Krebs solution was allowed to flow continuously through the segment. However, in the largest diameter segments the resting flow was very high, so flow was only recorded for 10-15 $\mathrm{s}$ at 1 min intervals. Each dose of drug was left in contact with the tissue until the response plateaued, this was about $1-1.5 \mathrm{~min}$ in the small segments, but $8 \mathrm{~min}$ in the largest segments, after either adventitial or mucosal exposure. The response to acetylcholine was not altered by the order of drug delivery (i.e. in/out versus out/in) (this study and [9]). In further experiments, the effect of acetylcholine was studied after gently removing the epithelial cells by rubbing with a moistened swab, which produced a greater than $80 \%$ loss of epithelium [9]. 


\section{Morphometry}

At the end of each experiment, the bronchial segment was fixed in formal saline. Wax embedded sections were stained lightly in haematoxylin and eosin (H\&E). A tracing of the epithelium of the distal portion of the segment was digitized using the chromatic image analysis system (Leading Edge Pty. Ltd, Bellevue Heights, South Australia), from which an ideal ID was calculated.

Morphological properties of airways of varying sizes were measured from duplicate sections of bronchi from four separate pigs. Freshly dissected bronchi were fixed for $4-8 \mathrm{~h}$ in formal sublimate $(200 \mathrm{ml} 40 \%$ formalin, $54 \mathrm{~g}$ mercuric chloride, made up to $2 \mathrm{l}$ ). After fixation, specimens were wax embedded. Sections, $7 \mu \mathrm{m}$, were stained with Picro-Mallory stain. Cross-sections of a large and small diameter bronchial segment are shown in figure 1 .

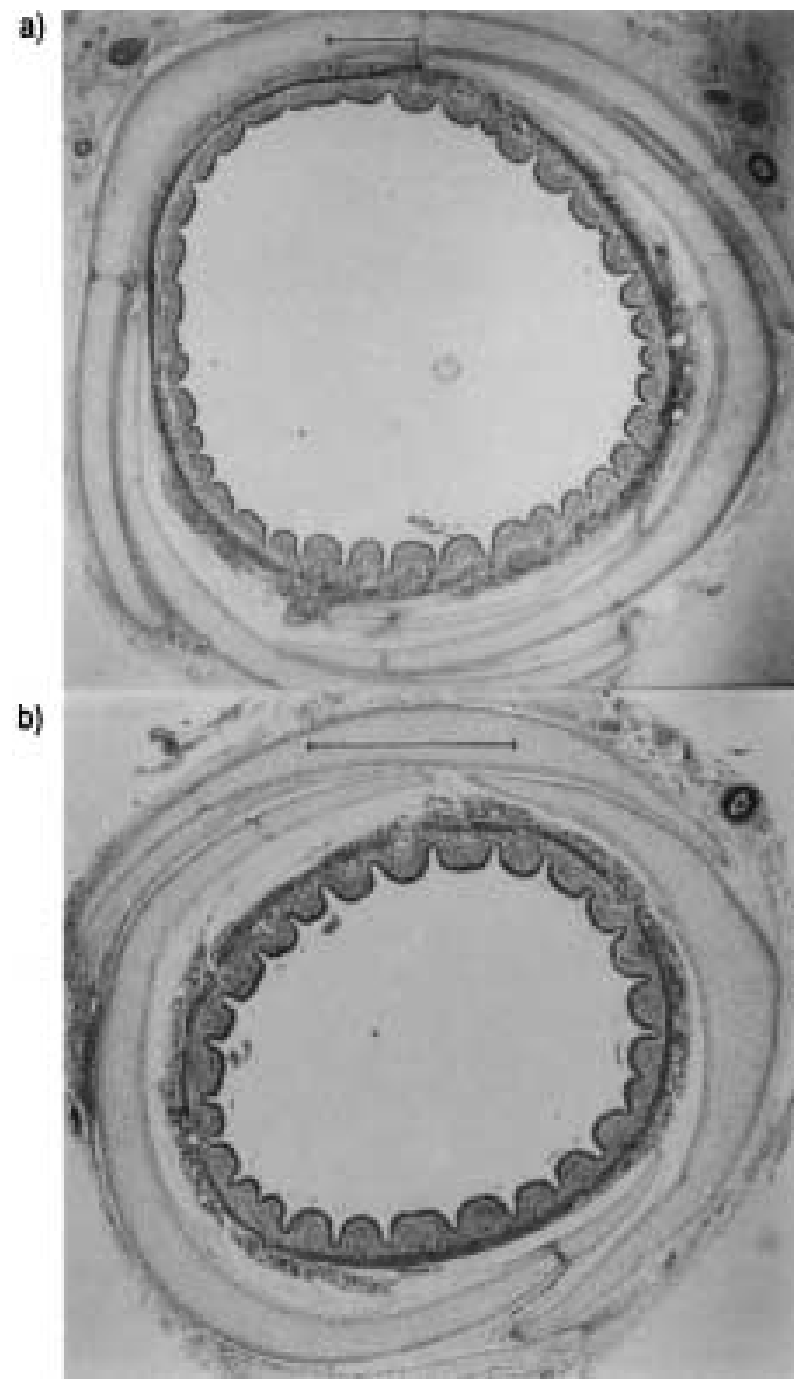

Fig. 1. - Sections of pig bronchus: a) large (approximately $6 \mathrm{~mm}$ internal diameter (ID); and b) small (2 mm ID). Bronchi dissected from fresh lungs were fixed without prior perfusion or inflation. (Calibration bars $=1 \mathrm{~mm}$ ).
Duplicate sections were analysed using the chromatic image analysis system. The primary measurements taken of airway cross-sections were as follows: 1) length of epithelium $\left(\mathrm{P}_{\mathrm{i}}\right)$; 2) lumen area (internal area, $\mathrm{A}_{\mathrm{i}}$ ); 3) perimeter of outer margin of smooth muscle (external perimeter, $\mathrm{P}_{\mathrm{e}}$ ); 4) area from epithelium to inner margin of smooth muscle (mucosal area); and 5) area $\left(\mathrm{A}_{\mathrm{e}}\right)$ enclosed by $\mathrm{P}_{\mathrm{e}}$.

The internal diameter of the fully relaxed circular airway was calculated from $\mathrm{P}_{\mathrm{i}}$. The wall area (WA) comprised the smooth muscle and mucosa, and was calculated by subtracting $A_{i}$ from $A_{e}$. The proportion of the fully relaxed airway cross-section made up by the wall (relative wall area) was $\mathrm{WA} /\left[\left(\mathrm{P}_{\mathrm{i}}^{2} / 4 \pi\right)+\mathrm{WA}\right]$. The average distance from the epithelium to the smooth muscle of a relaxed airway was estimated by subtracting the radius of a circle with circumference $P_{i}$ from the radius of a circle with an area defined by $\mathrm{P}_{\mathrm{i}}+$ mucosal area. The thickness of the cartilage to the external boundary of the smooth muscle was measured at eight points then averaged.

\section{Statistics}

The concentration of drug producing half maximum effect on flow $\left(\mathrm{EC}_{50}\right)$ was determined in each experiment. Where the drug caused the flow to stop, the $\mathrm{EC}_{50}$ was measured at the $50 \%$ flow reduction point and it was not, therefore, related to half of maximum muscle activation, but rather to the position of the concentration-response curve. Comparison between $\mathrm{pD}_{2}$ values $\left(-\log \mathrm{EC}_{50}\right)$ in different sized airways was made by analysis of variance (ANOVA) with Fisher's post hoc test using the StatZ software package (Western Statistical Computing, Nedlands, Australia). Student's t-test was used to analyse latencies and the effect of pressure on narrowing responses. Significance of the frequency of airway closure was calculated by $\chi^{2}$. A value of $\mathrm{p}<0.05$ was taken as significant. Curve fitting was carried out using software written by G. Yates, Department of Physiology, University of Western Australia. Data shown are mean \pm SEM.

\section{Results}

\section{Morphometry}

The IDs of the bronchial segments used in perfusion experiments with acetylcholine were determined by the morphometric measurement of the internal perimeter. The groups of segments had IDs (mean \pm SEM) of 1.52 \pm 0.09 , $2.00 \pm 0.32,2.59 \pm 0.14,3.74 \pm 0.42,4.85 \pm 0.49$ and $5.85 \pm 0.31$ $\mathrm{mm}$.

All airways studied were cartilaginous, and the smooth muscle layer extended round more than $90 \%$ of the circumference of the airway wall (fig. 1). The average distance from the adventitial margin of the cartilage to the smooth muscle increased from $0.41 \pm 0.03 \mathrm{~mm}$ in the smallest segments to $0.86 \pm 0.04 \mathrm{~mm}$ in the largest $(\mathrm{p}<0.001)$. 
The average distance from epithelium to smooth muscle (see Methods) increased from $0.102 \pm 0.008$ to $0.207 \pm 0.005$ $\mathrm{mm}(\mathrm{p}<0.001)$. The relative wall area (proportion of the airway cross-section made up by the wall) decreased with airway diameter from $0.22 \pm 0.02$ in the smallest bronchi to $0.15 \pm 0.02$ in the largest $(\mathrm{p}<0.05)$.



Fig. 2. - Resistance of bronchi of different internal diameters (IDs) recorded at resting flow rate under a $5 \mathrm{cmH}_{2} \mathrm{O}$ perfusion pressure. Each point is from one bronchial segment. Plot is resistance $=0.987 \pm 0.016(\mathrm{SEM}) /$ diameter $^{4}(\mathrm{p}<0.001)$.

\section{Bronchial responsiveness}

At a perfusion pressure of $5 \mathrm{cmH}_{2} \mathrm{O}$ the resting flow rates through segments $(\mathrm{n}=4-9)$ of different diameters $(\mathrm{mm})$ was $10.7+1.1 \mathrm{ml} \cdot \mathrm{min}^{-1}(1.52 \mathrm{~mm}) ; 22.3 \pm 2.4 \mathrm{ml} \cdot \mathrm{min}^{-1}(2.00$ $\mathrm{mm}) ; 44.2 \pm 1.7(2.59 \mathrm{~mm}) ; 77.7 \pm 8.3 \mathrm{ml} \cdot \mathrm{min}^{-1}(3.74 \mathrm{~mm})$; $404.3 \pm 20.5 \mathrm{ml} \cdot \mathrm{min}^{-1}(4.85 \mathrm{~mm})$; and $495.0 \pm 37.7 \mathrm{ml} \cdot \mathrm{min}^{-1}$ $(5.85 \mathrm{~mm})$. The relationship between the resting diameter and bronchial resistance is shown in figure 2 .

The data were best described by a fourth power function: resistance $=0.987 \pm 0.016 /$ diameter $^{4}(r=0.9259, p<0.001)$.

The flow of the perfusate through the segments was reduced by electrical field stimulation (EFS) and acetylcholine. We compared maximum responses to EFS (20 $\mathrm{Hz}, 2 \mathrm{~ms}, 60 \mathrm{~V}$ ) in small-bore (2-2.5 mm ID) and largebore (5-6 mm ID) segments at different perfusion pressures, to determine the optimal transmural pressure. An example of the experimental protocol is shown in figure 3. Maximum flow reduction to EFS was greater in smallthan large-bore segments at all pressures studied. For example, at $5 \mathrm{cmH}_{2} \mathrm{O}$, EFS caused a $68 \pm 6 \%(\mathrm{n}=4)$ reduction in flow in small segments, but a $39 \pm 10 \% \quad(n=4)$ reduction in flow in the large segments $(\mathrm{p}<0.05)$. In large diameter segments the percentage reduction in flow to EFS was almost the same at 5, 10, 15 and $20 \mathrm{cmH}_{2} \mathrm{O}$ (e.g. $39 \pm 10$ versus $29 \pm 10 \%$ at 5 and $20 \mathrm{cmH}_{2} \mathrm{O}$, respectively, (NS)). In small diameter segments the response was gradually reduced as pressure increased (from $68 \pm 6 \%$ at $5 \mathrm{cmH}_{2} \mathrm{O}$ to $41 \pm 6 \%$ at $\left.20 \mathrm{cmH}_{2} \mathrm{O},(\mathrm{p}<0.05)\right)$. a) Small segment

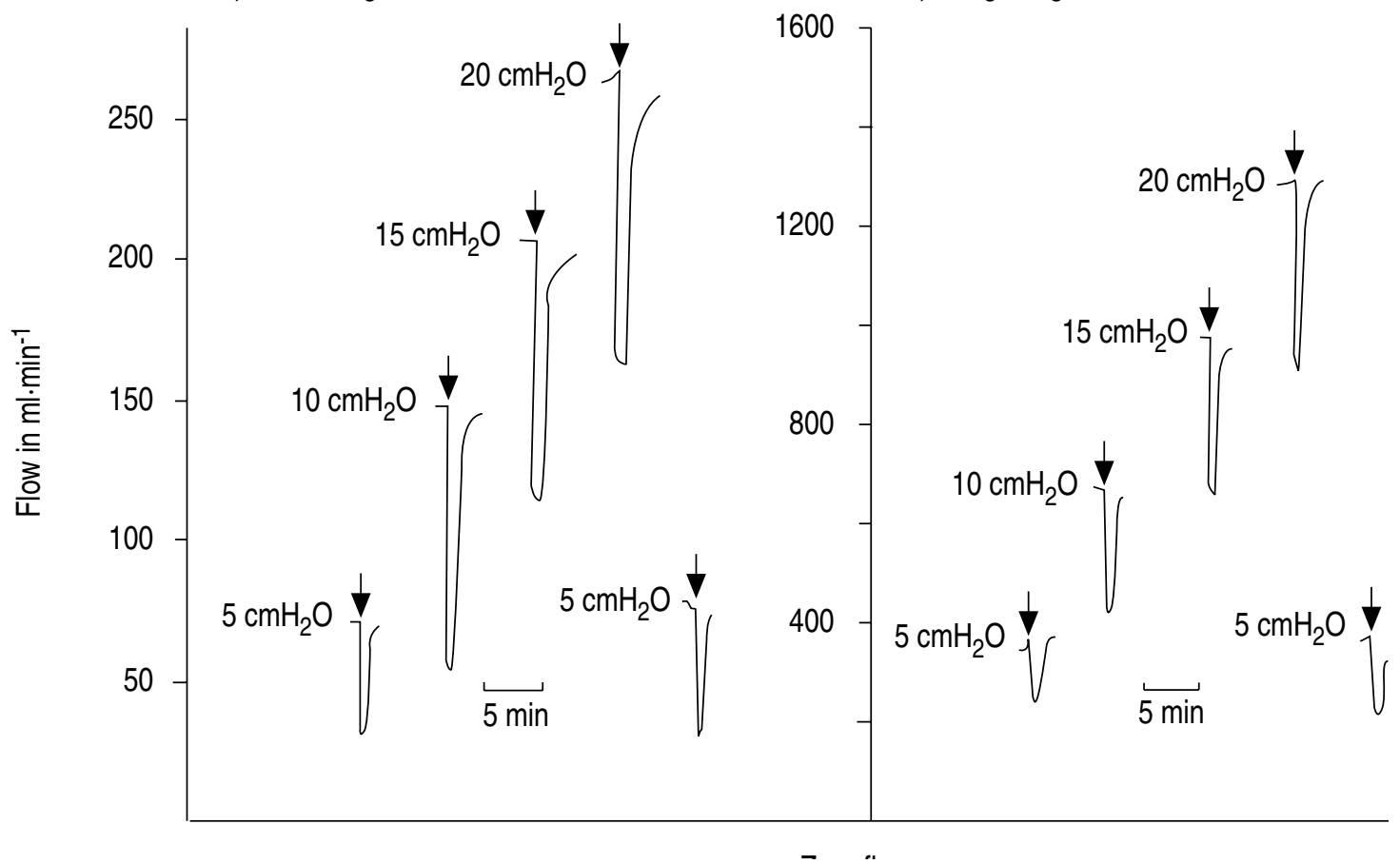

Fig. 3. - Flow rate through a small (2-2.5 $\mathrm{mm} \mathrm{ID)} \mathrm{and} \mathrm{large} \mathrm{(5-6} \mathrm{mm} \mathrm{ID)} \mathrm{diameter} \mathrm{bronchial} \mathrm{segment} \mathrm{at} \mathrm{different} \mathrm{perfusion} \mathrm{pressures.}$ Pressure was increased stepwise from $5,10,15$ to $20 \mathrm{cmH}_{2} \mathrm{O}$ (set from the height of the reservoir); then returned to $5 \mathrm{cmH} \mathrm{H}_{2} \mathrm{O}$. After each change in perfusion pressure the segment was electrical field stimulated $(20 \mathrm{~Hz}, 2 \mathrm{~ms}, 60 \mathrm{~V}$ indicated by arrow) to record a narrowing response. In small diameter segments the narrowing response tended to be less (as a $\%$ fall in flow) at high pressures ( $<<0.005$ between mean \% change in flow rate at 5 vs $20 \mathrm{cmH}_{2} \mathrm{O} ; \mathrm{n}=4$; see Results). In large diameter segments there was no significant difference in responses at different perfusion pressures. 
The acetylcholine-induced changes in the flow rate were concentration-dependent, whether the drug was given on the inside or the outside of the segments. In small diameter segments, responses to acetylcholine were prompt, but the latency time between addition of the drug and the onset of the narrowing response was less on the inside, $7.3 \pm 1.6 \mathrm{~s}$, compared with the outside $34.5 \pm 4.6 \mathrm{~s}(\mathrm{p}<0.001)$. In large-bore segments, responses to acetylcholine perfused through the inside $(3.5 \pm 0.8 \mathrm{~s})$ had a similar latency to the small diameter segments, but when given by the adventitial surface responses took several minutes in their onset $(252.0 \pm 18.0 \mathrm{~s},(\mathrm{p}<0.001)$, compared with inside and with small diameter segments).

There were major differences in the sensitivity and the maximum response to acetylcholine applied to the adventitial surface of large and small diameter bronchial segments (fig. 4). The concentration of acetylcholine producing half maximum effect increased strikingly in airways of increasing sizes with an approximate 870 fold difference in sensitivity between the smallest and largest diameter segments (table 1). High concentrations of acetylcholine invariably produced airway closure (i.e. flow rate reduced $>95 \%$ control) in small segments, e.g. in 4/4 experiments in $1.52 \mathrm{ID} \mathrm{mm} \mathrm{segments,} \mathrm{and} 4$ out of 5 experiments in $2.00 \mathrm{~mm}$ ID segments. However, in large diameter segments closure was not obtained $(\mathrm{p}<0.05)$, comparing incidence of closure in 2.00 versus $5.85 \mathrm{~mm}$ segments).

Response to acetylcholine in different sized airways was further compared in small-bore (mean ID, $2.00 \mathrm{~mm}$ ) and large-bore (mean ID, $5.85 \mathrm{~mm}$ ) segments (fig. 5 and table 1). When acetylcholine was perfused through the lumen, the sensitivity difference between small and large diameter airways was reduced to 42 fold (compared with 148 fold on the adventitia). After gently removing the epithelium (see Methods) this sensitivity difference was largely reduced to only five-fold (NS). The differences in maximum effect remained. In small segments, the highest concentrations of acetylcholine stopped the flow in 6 out of 10 experiments, but in large diameter segments airway closure did not occur in 8 experiments, $(\mathrm{p}<0.05)$.



Fig. 4. - Effect of acetylcholine on the flow rate in bronchial segments $(n=4-9)$ with different internal diameters (IDs). Acetylcholine was added to the outside (adventitial surface) of the segments. The ID of each segment was determined at the conclusion of the experiment from the length of the internal perimeter. Horizontal bars: \pm SEM of $\mathrm{EC}_{50}$. For statistical comparison see table 1. - $: 1.52$ $\mathrm{mm} \mathrm{ID} ; \multimap-2.00 \mathrm{~mm} \mathrm{ID} ;-\square: 2.59 \mathrm{ID} ; \square-: 3.74 \mathrm{~mm}$ ID; $\smile: 4.85 \mathrm{~mm} \mathrm{ID} ; \multimap$ : $5.85 \mathrm{~mm}$ ID. $\mathrm{EC}_{50}$ : concentration of drug producing half maximum effect on flow rate.

The above differences in sensitivity and maximum response between small and large airways were also present with carbachol as the agonist (fig. 6). As seen with acetylcholine, carbachol was approximately 20 times more potent when given on the outside than on the inside of small diameter segments, but was virtually equipotent on the inside and outside of large diameter segments. Airway closure was present at high drug concentrations in each of the small segments, but in none of the large segments $(\mathrm{n}=8, \mathrm{p}<0.05)$.

Table 1. - Sensitivity of bronchial segments to acetylcholine

\begin{tabular}{|c|c|c|c|c|c|c|}
\hline \multirow[b]{2}{*}{$\mathrm{pD}_{2}$} & \multicolumn{6}{|c|}{ Bronchial ID $\mathrm{mm}$} \\
\hline & 1.52 & 2.00 & 2.59 & 3.74 & 4.85 & 5.85 \\
\hline Outside & $\begin{array}{c}6.25 \pm 0.19 \\
(n=4)\end{array}$ & $\begin{array}{c}5.48 \pm 0.07 \\
(\mathrm{n}=5)\end{array}$ & $\begin{array}{c}4.52 \pm 0.34 \\
\quad(\mathrm{n}=6)\end{array}$ & $\begin{array}{l}4.27 \pm 0.21 \\
\quad(n=4)\end{array}$ & $\begin{array}{c}4.20 \pm 0.15 \\
\quad(n=4)\end{array}$ & $\begin{array}{c}3.31 \pm 0.39 \\
(\mathrm{n}=9)\end{array}$ \\
\hline $\begin{array}{l}\text { Inside epithelium } \\
\text { intact }\end{array}$ & - & $\begin{array}{c}4.33 \pm 0.19 \\
(\mathrm{n}=4)\end{array}$ & - & - & - & $\begin{array}{c}2.71 \pm 0.26 \\
(\mathrm{n}=4)\end{array}$ \\
\hline $\begin{array}{l}\text { Inside epithelium } \\
\text { denuded }\end{array}$ & - & $\begin{array}{l}5.57 \pm 0.25 \\
(\mathrm{n}=10)\end{array}$ & - & - & - & $\begin{array}{c}4.89 \pm 0.33 \\
(\mathrm{n}=8)\end{array}$ \\
\hline
\end{tabular}

$\mathrm{pD}_{2}$ values (negative $\log \mathrm{EC}_{50}$ ) for acetylcholine stimulation of bronchial segments; to the outside; inside; or inside denuded of epithelium. Sensitivity of small versus large diameter segments was significantly different $(\mathrm{p}<0.01-0.001)$ to acetylcholine outside and inside with intact epithelium, but not after denuding the epithelium. In small and large segments, removing the epithelium significantly increased sensitivity to acetylcholine inside $(\mathrm{p}<0.01-0.001)$. $\mathrm{EC}_{50}$ : concentration of drug producing half maximum effect on flow rate. 

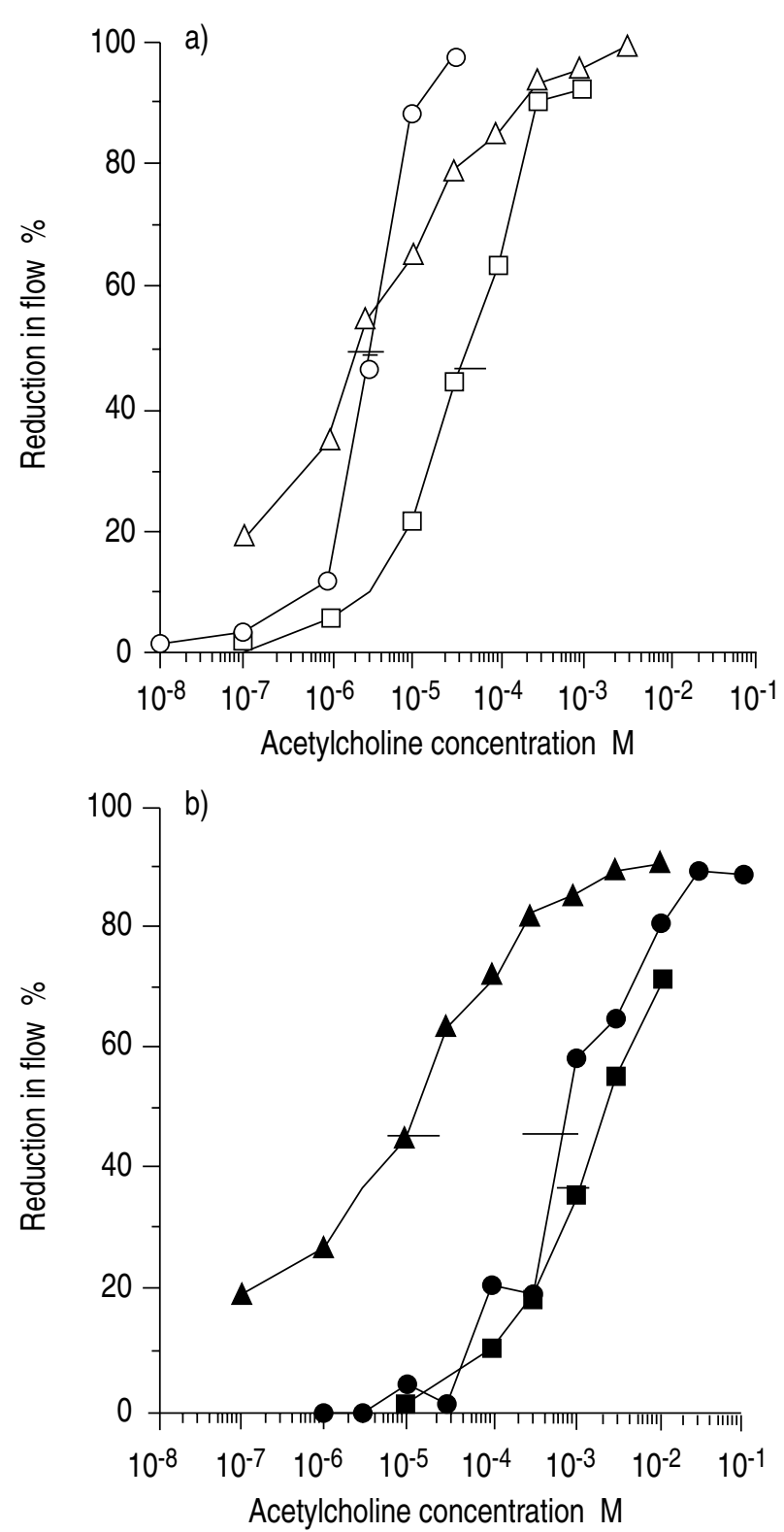

Fig. 5. - Effect of acetylcholine on the flow rate in: a) small (2.00 $\mathrm{mm}$ ID) diameter bronchial segments $(\mathrm{n}=4-10)$ and $\mathrm{b})$ large $(5.85 \mathrm{~mm}$ ID) diameter bronchial segments $(n=4-10)$. In each, curves for acetylcholine given to the outside (adventitia), inside (lumen), and inside after removing the epithelium are shown. Horizontal bars: \pm SEM of $\mathrm{EC}_{50}$. For statistical comparison see table 1. - (adventitia),$\square-$ : inside (lumen); $\triangle \square$ : inside after removing epithelium. Closed symbols are for large diameter, open symbols for small diameter. $\mathrm{EC}_{50}$ : concentration of drug producing half maximum effect on flow rate.

\section{Discussion}

The narrowing characteristics of individual airways from different anatomical locations in vitro have not been studied previously, despite their predicted importance to the responsiveness of the lung. The present findings demonstrate the responsiveness of the bronchi in the absence of external support from lung tissue or influence from changes in lung volume seen in vivo. The approach used was to measure the parameter of flow, which is

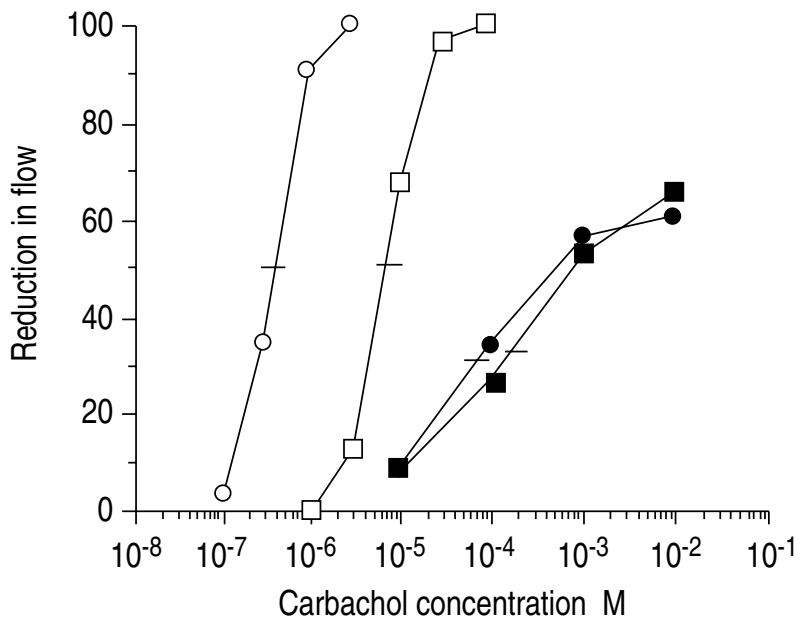

Fig. 6. - Effect of carbachol on the flow rate in small (2-2.5 mm ID) and large (5-6 mm ID) diameter bronchial segments $(n=4)$. Carbachol was given on either the inside (lumen) or outside (adventitia) of the segment. Horizontal bars: $\pm \mathrm{SE}$ or $\mathrm{EC}_{50}$. The $\mathrm{EC}_{50} \mathrm{~s}$ were significantly different $(\mathrm{p}<0.01)$ in small diameter segments but not in large. $-0-$ : small, outside (adventitia); —— : large outside (adventitia); $\square-\square$ : small, inside (lumen); $\quad$ rge inside (lumen). $\mathrm{EC}_{50}$ : con- centration of drug producing half maximum effect on flow rate.

related to the diameter of the bronchi and, therefore, to muscle shortening after drug challenge. We demonstrated here that resistance in unstimulated bronchial segments was closely related to the fourth power of the radius. Poiseuillian flow has been assumed by others when modelling the effect of muscle shortening on flow resistance [13, 14], but this has not been tested in individual airways (such as those used in our study) where the lumen is probably noncircular and there are side branches.

By utilizing isolated, but otherwise intact, segments of bronchus of the desired internal diameter, we were able to largely control several parameters, such as driving pressure, surface exposed to drug and the dosage applied to the preparation. The bronchial wall of all segments used (large and small) had a similar structure, and all had overlapping cartilage plates; this facilitated a comparison of responses in different segment preparations. The concentration of drug actually present at the smooth muscle layer depended on concentration gradients across the airway wall, which are influenced by diffusion barriers, such as cartilage or epithelium. Experiments were conducted using a $5 \mathrm{cmH}_{2} \mathrm{O}$ driving pressure, which we have found to give optimal narrowing. We found that the extent of airway narrowing did not vary markedly between 5 and $10 \mathrm{cmH}_{2} \mathrm{O}$, which is compatible with previous findings in isovolumic bronchial segments [10]. At higher pressures, responses in small segments were reduced, which could occur if the smooth muscle moved along its length-force curve in a compliant airway, or with the introduction of a significant preload [18, 19]. The insensitivity of airway narrowing to small variations in transmural force indicate that small changes in the pressure drop along a constricting segment (i.e. up to 2.5 $\mathrm{cmH}_{2} \mathrm{O}$, see Methods) would have a negligible effect on responsiveness. It may be interesting to determine the 
effect of negative forces applied to the adventitial cartilage, to mimic an effect of attached parenchyma, on the responsiveness of airway narrowing.

A major effect of bronchial size on position (sensitivity) and maximum effect of concentration-response curves to cholinergic drugs has been demonstrated. To adventitial stimulation with acetylcholine the sensitivity difference was up to 870 fold between the largest and smallest bronchi examined. With mucosal provocation, the sensitivity difference was less, but still substantial, and for $2.00 \mathrm{~mm}$ and $5.85 \mathrm{~mm}$ ID bronchi amounted to a 42 fold difference. As shown previously, the sensitivity of the smooth muscle from distal and proximal parts of the bronchial tree in the pig is practically identical $[20,21]$, indicating that the differences in responsiveness described here are seen only when the physical or morphological structure of the airway wall is present.

Both the adventitial and mucosal diffusion distances to the smooth muscle progressively decreased from large to small bronchi, which, for adventitial exposure, probably accounted, in part, for the faster onset of narrowing observed in the small segments (252s to $34 \mathrm{~s}$ ) [22], and may also contribute to the differences in sensitivity. However, it was improbable that differences in drug concentrations in the outer and inner solutions accounted for the observed differences in bronchial responsiveness between large and small airways, because in small airways flow through the lumen was low and in large airways flow was intermittent and for the most part absent (see Methods). Furthermore, we have observed similar sensitivity shifts to adventitial drug application under near equilibrium conditions in isovolumic large and small bronchi (personal communication, T.I. Omari and P.G. Gray, Department of Physiology, University of Western Australia).

We suggest that the tension generated by the smooth muscle could produce greater muscle shortening in small airways and greater narrowing sensitivity, and that the size of the lumen and wall of the small-bore airway amplifies narrowing responsiveness. The impermeant properties of the epithelium to charged and hydrophylic molecules play a dominant role in responsiveness, and the present findings suggest that these are different at different anatomical locations of airway. This was evidenced by the 42 fold greater sensitivity of small bronchi to mucosal drug provocation. After removing the epithelium this sensitivity difference was much reduced, so that the small and large bronchi only varied approximately five fold.

Previous studies on the intact bronchus of the pig showed that responses are not affected by putative relaxant substances [9].

Airway narrowing was greater in small diameter bronchi $(<3 \mathrm{~mm})$ than large, and this produced functional closure at the peripheral sites but a plateau in the proximal airways. The greater maximum effect was observed to EFS, acetylcholine, and to carbachol, administered either intraluminally or adventitially. This was not due to increased thickness of smooth muscle in small airways, since it was thinner [23] (fig. 1), nor to increased sensitivity or force produced by the smooth muscle cells $[20$,
21]. The observation can be explained by the greater relative wall area in the small diameter bronchi, so that airway occlusion takes place before maximal smooth muscle shortening. In the large diameter bronchi, maximum muscle shortening fails to produce complete encroachment of the lumen by bronchial wall. Although this has been predicted from hypothetical models of airway behaviour [13, 14], it has not hitherto been demonstrated in real airways without opposition from other lung forces.

The present experimental findings define differences in sensitivity of isolated bronchi to luminal and adventitial provocation in small and large airways, with small airways showing increased sensitivity of several orders of magnitude, depending on their diameter and on the route of drug application. However, the difference in large and small airway sensitivity determined by mucosal provocation is much less after the epithelium has been denuded, indicating that sensitivity is strongly dependent on drug access to the smooth muscle. However, a major effect of bronchial size is seen in the upper part of the dose-response curve, where closure occurs to acetylcholine in airways with small lumen diameter and greater relative wall area, but not in large diameter bronchi, where there is a plateau in the curve. In this respect our results support predictions $[13,14]$. Small airways have been implicated in flow reduction in some hyperresponsive individuals [24-27]. Furthermore, agonists may act preferentially on airways at central or peripheral locations [7, 28], and the present findings indicate that the location(s) of airways activated in the lung is an important variable in the response of narrowing, sensitivity and maximum effect.

Acknowledgements: The assistance of K. Yuen and D. Webster is gratefully acknowledged.

\section{References}

1. Woolcock AJ, Permutt S. Bronchial Hyperresponsiveness. In: Macklem PT, Mead J, eds. Handbook of Physiology. Baltimore, American Physiological Society, 1984; Vol. 3, Part 2, pp. 727-736.

2. Michoud MC, Paré PD, Boucher R, Hogg JC. Airway responses to histamine and methacholine in Ascaris suum allergic rhesus monkeys. J Appl Physiol: Respirat Environ Exercise Physiol 1978; 45: 846-851.

3. Holtzman MJ, Fabbri LM, O'Byrne PM, et al. Importance of airway inflammation for hyperresponsiveness induced by ozone. Am Rev Respir Dis 1983; 127: 686-690.

4. Pedley TJ, Schroter RC, Sudlow MF. The prediction of pressure drop and variation of resistance within the human bronchial airways. Respir Physiol 1970; 9: 387-405.

5. Hogg JC, Macklem PT, Thurlbeck WA. Site and nature of airway obstruction in chronic obstructive lung disease. N Engl J Med 1968; 278: 1355-1360.

6. Macklem PT, Woolcock AJ, Hogg JC, Nadel JA, Wilson NJ. Partitioning respiratory system resistance in the dog. J Appl Physiol 1969; 26: 798-805.

7. Jackson AC, Loring SH, Drazen JM. Serial distribution of bronchoconstriction induced by vagal stimulation or histamine. J Appl Physiol: Respirat Environ Exercise Physiol 1981; 50: 1286-1292. 
8. Murphy TM, Roy L, Philips IJ, et al. Effect of maturation on topographic distribution of bronchoconstrictor responses in large diameter airways of young swine. Am Rev Respir Dis 1991; 143: 126-131.

9. Sparrow MP, Mitchell HW. The epithelium acts as a barrier modulating the extent of bronchial narrowing produced by substances perfused through the lumen. $\mathrm{BrJ}$ Pharmacol 1991; 103: 1160-1164.

10. Sparrow MP, McFawn PK, Omari TI, Mitchell HW. Activation of smooth muscle in the airway wall, force production and airway narrowing. Can J Physiol Pharmacol 1992; 70: 607-614.

11. Ariens EJ. Pharmacology of airway smooth muscle. In: Nadel JA, Pauwels R, Snashall PD, eds. Bronchial Hyperresponsiveness. Normal and Abnormal Control, Assessment and Therapy. Oxford, London, Edinburgh, Boston, Palo Alto and Melbourne, Blackwell Publications, 1987; pp. 7-22.

12. Freedman BJ. The functional geometry of the bronchi. Bull Pathophysiol Resp 1972; 8: 545-551.

13. James AL, Paré PD, Hogg JC. The mechanics of airway narrowing in asthma. Am Rev Respir Dis 1989; 139: 242-246.

14. Moreno RH, Hogg JC, Paré PD. Mechanics of airway narrowing. Am Rev Respir Dis 1986; 133: 1171-1180.

15. Wiggs BR, Bosken C, Paré PD, James AL, Hogg JC. A model of airway narrowing in asthmatic and in chronic obstructive pulmonary disease. Am Rev Respir Dis 1992; 145: 1251-1258.

16. Sparrow MP, Willet KE, Mitchell HW. Airway diameter determines flow-resistance and sensitivity to contractile mediators in perfused bronchial segments. Agents Actions 1990; 31 (Suppl.): 63-66.

17. Mitchell HW, Willet KE, Sparrow MP. Perfused bronchial segment and bronchial strip: narrowing vs. isometric force by mediators. J Appl Physiol 1989; 66: 2704-2709.

18. Ishida K, Paré PD, Blogg T, Schellenberg RR. Effects of elastic loading on porcine trachealis muscle mechanics. J Appl Physiol 1990; 69: 1033-1039.

19. Stephens NL, Van Nierkirk DW. Isometric and isotonic contractions in airway smooth muscle. Can J Physiol Pharmacol 1977; 55: 833-838.

20. Sparrow MP, Mitchell HW. Contraction of smooth muscle of pig airway tissues from before birth to maturity. J Appl Physiol 1990; 68: 468-477.

21. Mitchell HW, McFawn PK, Sparrow MP. Increased narrowing of bronchial segments from immature pigs. Eur Respir J 1992; 5: 207-212.

22. Crank L. In: The Mathematics of Diffusion. Oxford, Clarendon Press. 1975; pp. 44-68.

23. Ebina M, Yaegashi H, Criba R, Takahashi T, Motomiya M, Tanemura M. Hyperreactive site in the airway tree of asthmatic patients revealed by thickening of bronchial muscles. A morphometric study. Am Rev Respir Dis 1990; 141: 1327-1332.

24. McFadden ER, Ingram RH, Haynes RL, Wellman JJ. Predominant site of flow limitation and mechanisms of post-exertional asthma. J Appl Physiol 1977; 42: 746-752.

25. Bosken CH, Wiggs BR, Paré PD, Hogg JC. Small airway dimensions in smokers with obstruction to airflow. Am Rev Respir Dis 1990; 142: 563-570.

26. Sekizawa K, Sasaki H, Shimizu Y, Takishima T. Doseresponse effects of methacholine in normal and in asthmatic subjects. Relationship between the site of airway response and overall airway hyperresponsiveness. Am Rev Respir Dis 1986; 133: 593-599.

27. Fish JE, Rosenthal RR, Butra G, et al. Airway responses to methacholine in allergic and nonasthmatic subjects. Am Rev Respir Dis 1976; 113: 579-586.

28. Pichurko BM, Ingram RH, Sperling RI, et al. Localization of the site of the bronchoconstrictor effects of leukotriene $\mathrm{C}_{4}$ compared with that of histamine in asthmatic subjects. Am Rev Respir Dis 1989; 140: 334-339. 